УДК 621.391: 519.22

\title{
ФУНКЦИЯ КОГЕРЕНТНОСТИ ВЗАИМОСВЯЗАННЫХ ПЕРИОДИЧЕСКИ НЕСТАЦИОНАРНЫХ СЛУЧАЙНЫХ ПРОЦЕССОВ
}

\author{
ЯВОРСКИЙ И.Н. ${ }^{1,2}$, ЮЗЕФОВИЧ Р.М. ${ }^{1}$, МАЦЬКО И.Й. ${ }^{1}$, ЗАКЖЕВСКИ 3. ${ }^{2}$ \\ ${ }^{1}$ Физико-механический институт им. Г. В. Карпенко Национальной Академии наук Украинь, \\ Украина, Львов, 79601, ул. Научная 5 \\ ${ }^{2}$ Институт телекоммуникайий технологически-естествоведческого университета, \\ Польша, Быдгош, 85796, аллея проф. Калинского 7
}

\begin{abstract}
Аннотация. Предложена функция когерентности, характеризирующая коррелированость гармонических составляющих двух сигналов, которые описываются периодически коррелированными случайными процессами. Показано, что такая функция не изменяется при линейных преобразованиях сигналов. Формула для функции когерентности конкретизирована для амплитудно- и фазомодулированых сигналов
\end{abstract}

Ключевые слова: периодически нестационарный случайный процесс; коррелированность гармоник; функция когерентности; линейные преобразования

\section{ВСТУПЛЕНИЕ}

Необходимость в проведении взаимокорреляционного и взаимоспектрального анализа случайных процессов возникает при исследовании одно- и многоканальных систем передачи информаци, идентификации путей распространения сигналов, локализации их источников и др. [1-3]. Для количественного описания стохастических связей стационарных случайных сигналов $\xi(t)$ и $\eta(t)$ используется функция когерентности, которая определяется выражением $[2,3]$ :

$$
\gamma_{\xi \eta}(\omega)=\frac{\left|f_{\xi \eta}(\omega)\right|}{\left[f_{\xi}(\omega) f_{\eta}(\omega)\right]^{1 / 2}},
$$

где $f_{\xi \eta}(\omega)$ - взаимная спектральная плотность стационарно связанных сигналов, $f_{\xi}(\omega)$ и $f_{\eta}(\omega)$ - их спектральные плотности мощности. Поскольку $[2,3]$ :

$$
\left|f_{\xi \eta}(\omega)\right|^{2} \leq f_{\xi}(\omega) f_{\eta}(\omega)
$$

то для функции (1) всегда выполняется условие $0 \leq \gamma_{\xi \eta}(\omega) \leq 1$. Для независимых сигналов $\gamma_{\xi \eta}(\omega)=0$ для всех $\omega \in R$. Если сигналы $\xi(t)$ и $\eta(t)$ являются результатом линейных преобразований одного и того же процесса, то $\gamma_{\xi \eta}(\omega)=1$. Если функция когерентности меньше единицы, то возможны следующие ситуации:

a) на один из сигналов влияет внешний шум;

б) один из сигналов претерпел нелинейные преобразования;

в) на один из сигналов, кроме исследуемого, влияют другие.

При проведении анализа линейных систем функция когерентности (1) дает возможность выделить ту часть случайного сигнала $\eta(t)$, которая на частоте $\omega$ определяется процессом $\xi(t)$. С другой стороны, разность $1-\gamma_{\xi \eta}(\omega)$ ха- 